\title{
Onset rivalry: factors that succeed and fail to bias selection
}

\author{
Mouna Attarha • Cathleen M. Moore
}

Published online: 12 November 2014

(C) The Psychonomic Society, Inc. 2014

\begin{abstract}
This project examined whether previous visual history can bias perceptual dominance during onset rivalry. A predictive sequence of non-rivalrous stimuli preceded dichoptically presented rivalrous displays. One of the dichoptic images was the implied next step of the preceding sequence while the other was not. Observers reported their initial dominant percept. Across five experiments, we found that motion sequences biased perceptual selection such that a rivalrous stimulus that continued a motion sequence tended to dominate one that did not. However, signals generated by complex pattern of motion information or verbal-semantic information had no influence on selection. These results are consistent with the view that onset rivalry is an early phase of rivalry that is likely insensitive to modulation by factors originating beyond the visual system.
\end{abstract}

Keywords Onset binocular rivalry $\cdot$ Rivalry entrainment . Initial dominance $\cdot$ Motion $\cdot$ Prediction

The phenomenon of binocular rivalry is observed when two featurally dissimilar images, such as a house and a face, are presented dichoptically to corresponding retinal locations of the two eyes. Although the images stimulate the two retinae simultaneously, fusion fails and the percepts associated with each separate image alternate in temporal cycles of dominance

Electronic supplementary material The online version of this article (doi:10.3758/s13414-014-0793-1) contains supplementary material, which is available to authorized users.

M. Attarha $(\bowtie) \cdot$ C. M. Moore

Department of Psychology, University of Iowa, E11 Seashore Hall, Iowa City, IA 52242-1407, USA

e-mail: mouna.attarha@gmail.com

C. M. Moore

e-mail: cathleen-moore@uiowa.edu and suppression (e.g., Levelt 1967; Wheatstone, 1838). These alternating percepts reflect fluctuations in neural activity that correspond specifically to each of the different perceptual outcomes (Leopold \& Logothetis, 1996; Lin \& He, 2009; Logothetis, 1998; Logothetis \& Schall, 1989; Tong, Meng, \& Blake, 2006). It is this potential for relating specific neural activity to conscious visual awareness that has made binocular rivalry a focus of study for many psychologists, neuroscientists, and philosophers (Breese, 1909; Crick \& Koch, 2003; de Jong, Kourtzi, \& van Ee, 2012a; Haynes, Deichmann, \& Rees, 2005; Lee, Blake, \& Heeger, 2005; O’Shea, Kornmeier, \& Roeber, 2013; Tong \& Engel, 2001; Wheatstone, 1838; see Blake \& Logothetis, 2002; Maier, Panagiotaropoulos, \& Tsuchiya, 2012 for reviews; c.f., Blake, Brascamp, \& Heeger, 2014).

The temporal dynamics of alternating dominance and suppression are a hallmark feature of binocular rivalry. If all other factors between two rivalrous images are held constant, then the two percepts tend to dominate visual awareness over time with approximately equal frequency, following a stochastic pattern (Levelt 1967; Fox \& Herrmann, 1967; Kim, Grabowecky, \& Suzuki, 2006). Introducing low-level featural asymmetries between the images, such as differences in contrast, luminance, motion, or contour density, however, alters the dynamics of binocular rivalry by causing the percept of the more intense stimulus to have shorter periods of suppression, and consequently longer periods of dominance (Breese, 1909; Fahle, 1982; Kaplan \& Metlay, 1964; Levelt 1967; Mueller \& Blake, 1989; Wheatstone, 1838). The transition between the dominant and suppressed images does not occur instantaneously. Rather, it tends to occur in a piece-meal fashion, whereby portions of the suppressed image appear in one region of the dominant image and spatially propagate across the rest of the image in a wavelike manner (Wilson, Blake, \& Lee, 2001). Patterns of dominance and suppression continue for as long as the visual conflict is present. 
Research on binocular rivalry over the last several decades has revealed that the successive periods of dominance and suppression can be separated into at least three general stages. First, when the two dichoptically presented images are presented for $150 \mathrm{~ms}$ or less, false fusion occurs (Wolfe, 1983; see also Blake, Yang, \& Westendorft, 1991), which is the perceived superimposition of the dichoptic stimuli (as distinct from optical fusion; Georgeson \& Meese, 1997). The existence of false fusion early on indicates that rivalry takes time to develop. Following false fusion is the sequence of alternating dominance and suppression of the two images known generally as binocular rivarly. However, the initial period of dominance - referred to as onset rivalry - has been shown to be dissociable in terms of underlying processes from the subsequent period of ongoing dominance, which is referred to as sustained rivalry to distinguish it from onset rivalry (see Stanley, Forte, Cavanagh, \& Carter, 2011 for a review). Carter and Cavanagh (2007), for example, presented a pair of orthogonal gratings dichoptically at different spatial locations and observers reported successive periods of dominance under conditions of brief $(1 \mathrm{sec})$ and sustained viewing $(60 \mathrm{sec})$. Under brief presentation, areas of the visual field were strongly biased toward one image over another, such that an observer exclusively reported seeing the same image at a given location across many trials. These biases, while idiosyncratic across observers, were highly reliable within observers, not only over the course of a particular experiment but also for weeks afterward. In contrast, during sustained viewing, the rivalrous images dominated equally often and no biases of dominance were observed. It appears that unlike the dynamics of sustained rivalry, selection at onset is highly stable (Carter \& Cavanagh, 2007; Kim et al., 2006; Pearson \& Brascamp, 2008; van Ee, 2009).

The differences between onset rivalry and sustained rivalry led Carter and Cavanagh (2007) to conclude that dominance at onset can be characterized as an early phase of rivalry that is independent from a later sustained phase (see also Chong \& Blake, 2006; Crovitz \& Lipscomb, 1963; de Jong, Knapen, \& van Ee, 2012; Kalisvaart, Rampersad, \& Goossens, 2011; Leat \& Woodhouse, 1984; Sheth \& Pham, 2008; Song \& Yao, 2009; Stanley et al., 2011). Carter and Cavanagh found that the persistent dominance of one rivalrous image over another in onset rivalry is attributed to low-level, spatially localized endogenous factors, which in a series of follow-up experiments could not be fully accounted for by other low-level factors, such as eye-based regions of monocular dominance, sensory memory, or adaptation over the course of the trial. Because the robust patterns of dominance were location specific, onset rivalry is particularly well suited for studying early perceptual conflict and, as the Carter and Cavanagh suggest, likely insensitive to top-down, exogenous influences.

The view that onset rivalry is insensitive to top-down signals was brought into question by a study that showed that prior predictive stimulus context could bias which eyes percept was dominant in onset rivalry (Denison, Piazza, \& Silver, 2011). The predictive context consisted of a temporal stream of stimuli in which gratings rotated clockwise or counterclockwise in steps of 45 degrees. The same sequence was presented to the left and right eyes, thereby yielding an unambiguous (i.e., nonrivalrous) perception of apparent rotational motion. The sequence ended with two orthogonally oriented gratings presented dichoptically and observers reported the initial dominant percept (i.e., the resolution of onset rivalry). The orientation of one of the two dichoptically presented gratings was that which would have continued the motion trajectory that was established by the preceding motion sequence. Because the orientation of the other grating was orthogonal to this, it would imply an abrupt change of motion direction. Onset rivalry dominance was biased toward the image that continued the motion sequence, suggesting that top-down predictive signals, produced by past information, influence perceptual selection in early cortical areas during rivalry. Control experiments and arguments indicated that the bias effect on onset dominance could not be fully accounted for by priming, adaptation, or attention.

Denison et al. (2011) proposed that Bayesian models of predictive coding (e.g., Friston, 2005; Hohwy, Roepstorff, \& Friston, 2008; Rao \& Ballard, 1999; see also Alink, Schwiedrzik, Kohler, Singer, \& Muckli, 2010; Summerfield \& Koechlin, 2008) could provide a useful framework for understanding how selection processes that determine dominance in onset rivalry could be constrained by past experience. Generally, these models suggest that hierarchically-late stages of processing continuously generate predictions, or "perceptual hypotheses," regarding the activity in lower stages of processing based on both incoming information and information received in the recent past. The perceptual hypothesis with the highest probability, given both the current incoming data and the past likelihood, determines perceptual selection. Event-related potentials, such as mismatch negatively and the visual mismatch negativity, may be the electrophysiological index of the residual error between statistical prediction and the input signal (e.g., den Ouden, Kok, \& de Lange, 2012; Garrido, Kilner, Stephan, \& Friston, 2009; Lee \& Mumford, 2003; Näätänen, 1992; Stefanics \& Czigler, 2012; Stefanics, Kremlacek, \& Czigler, 2014; Wacongne, Changeux, \& Dehaene, 2012).

With regard to binocular rivalry, in particular, the idea of predictive coding as suggested by Denison et al. (2011) is that the bottom-up signal coming from the unpredicted stimulus is less consistent with the high-probability perceptual hypothesis than the other stimulus and therefore is inhibited. A switch in dominance in favor of an unpredicted percept can be triggered eventually when the unexplained prediction error, which continues as long as the competing stimulus is presented to the other eye, contributes sufficiently to the past likelihood of the 
alternative perceptual hypothesis as to make dominance unstable and competition open again.

If predictive coding accounts for the bias in favor of continued motion direction under rivalrous conditions (Denison et al., 2011), then it might similarly account for other reported top-down effects on onset dominance, such as perceived task utility (Chopin \& Mamassian, 2010), emotional salience (Gray, Adams, \& Garner, 2009; but see Sheth \& Pham, 2008), categorical adaptation (Pelekanos, Roumani, \& Moutoussis, 2011), and object-based attention (Mitchell, Stoner, \& Reynolds, 2004). In general, an expected (more likely) stimulus may benefit from improved processing speed, recognition, and visibility which in turn would lead to increased dominance under rivalrous conditions (e.g., Melloni, Schwiedrzik, Müller, Rodriguez, \& Singer, 2011; Esterman \& Yantis, 2010; Dolan et al., 1997).

Although it is well established that top-down cognitive factors can influence average dominance during sustained rivalry (e.g., Anderson, Siegel, Bliss-Moreau, \& Barrett, 2011; Mudrik, Deouell, \& Lamy, 2011; Wolf \& Hochstein, 2011), the role that these factors play during onset rivalry remains less clear. As noted, onset rivalry appears to be mediated by at least partially different processes than those underlying sustained rivalry (Carter \& Cavanagh, 2007). Identifying those factors that do and do not bias dominance in onset rivalry could provide a better characterization of how this stage of rivalry differs from the other. With this goal in mind, we examined the extent to which different types of recent visual history could bias dominance in onset rivalry. In each case, a non-rivalrous stimulus stream preceded a dichoptically presented rivalrous display. One of the dichoptic images was consistent with a continuation of the preceding non-rivalrous history, while the other was inconsistent. The level of representation at which consistency was defined was varied across experiments (e.g., motion signal versus semantic information). Experiments 1 and 2 replicated Denison et al.'s test of predictive direction of apparent motion. Experiment 3 tested predictive semantic information using verbal stimuli. Experiments 4 and 5 tested a predictive pattern of motion, which was dissociated from direction of motion. By way of preview, dominance for onset rivalry was biased only by the predictive direction of motion. Neither prediction based on semantic information nor prediction based on the global pattern of motion was sufficient to bias dominance of onset rivalry.

\section{Experiment 1}

Experiment 1 was essentially a replication of Denison et al.'s (2011) test of whether onset rivalry could be entrained by the direction of apparent-motion sequences. Trials consisted of a predictive sequence of non-rivalrous gratings that rotated either clockwise or counterclockwise. The sequence was always followed by a rivalrous display of two orthogonal gratings, one presented to each eye. The orientation of one of the rivalrous gratings was the next step in the sequence of motion that preceded it and therefore was consistent with the sequence of motion. The other grating was orthogonal to the next step in the sequence of motion and therefore was inconsistent with the sequence of motion. Reports of the dominant percept were compared to a baseline condition that had no preceding motion sequence. The logic was that if the resolution of onset rivalry is insensitive to motion direction, then no differences between the entrained conditions (i.e., those including a preceding motion sequence) and the control condition should occur. Alternatively, if onset rivalry can be biased by motion direction, then the orientation of the reported initial percept should be consistent with the motion trajectory for entrained relative to control conditions. Like Denison et al. before us, this is what we found.

\section{Method}

Observers Eleven undergraduate volunteers from the University of Iowa participated in exchange for course credit (1 male, 10 female, age range: 18-24 years, 1 left-handed). All observers were naïve to the purpose of the study and reported normal visual acuity and color vision. Stereovision was confirmed using the stereo fly test (Titmus Fly, Stereo Optical Co, Chicago, IL). Observers were recruited in accordance with the University of Iowa Internal Review Board (IRB)-approved polices and procedures.

Equipment Stimuli were displayed on a flat-screen cathode ray tube monitor (19-inch ViewSonic G90fB) controlled by a Macintosh Pro (Mac OS X) with a 512 MB NVIDIA GeForce 8800 GT graphics card (1024 by 768 pixels, viewing distance of $61.50 \mathrm{~cm}$, horizontal refresh rate of $100 \mathrm{~Hz}$ ). Stimuli were generated using the Psychophysics Toolbox Version 3.0.8 (Brainard, 1997; Pelli, 1997) for MATLAB (Version 7.5, Mathworks, MA). Observers were seated in a heightadjustable chair and used an adjustable chin rest to maintain a constant viewing distance from the computer monitor. All displays were viewed through a mirror stereoscope that was adjusted for each observer.

Stimuli Visual stimuli were circular patches of square wave gratings $\left(1.86^{\circ}\right.$ in diameter; $\left.32 \mathrm{~cd} / \mathrm{m}^{2}\right)$ framed by a black annulus to promote alignment $\left(2.60^{\circ}\right.$ annulus diameter, $0.19^{\circ}$ annulus thickness). All gratings had a spatial frequency of 3 cycles per degree (CPD) and were presented at $30 \%$ contrast on a neutral gray background $\left(53 \mathrm{~cd} / \mathrm{m}^{2}\right)$.

Procedure Observers completed one $\sim 60$-minute session that consisted of a practice block of 7 trials, followed by 6 
experimental blocks of 32 trials each. Practice trials were excluded from all analyses.

Trial events are illustrated in Fig. 1. On entrain conditions, a predictive sequence of stimuli was presented simultaneously to both eyes prior to presenting the conflicting images to the two eyes. The starting orientation of the gratings in the predictive sequence was either $+45^{\circ}$ or $-45^{\circ}$, and the sequence always consisted of four sequentially presented gray gratings that rotated clockwise or counterclockwise in discrete steps of $45^{\circ}$. Perception was non-rivalrous, because the same stimuli were presented to the left and right eyes. Each stimulus in the predictive sequence was available for $300 \mathrm{~ms}$, followed by a $100 \mathrm{~ms}$ blank period where only the annulus frame persisted. Two baseline conditions were included to determine how often each rivalrous grating was selected in the absence of entrainment. On blank conditions, no gratings were presented and only the black annulus preceded the rivalrous display. On plaid conditions, the gray gratings in the clockwise and counterclockwise predictive sequences were spatially overlaid. This gave rise to the perception of a plaid that alternated between oblique orientations $\left( \pm 45^{\circ}\right)$ and cardinal orientations $\left(0^{\circ}, 90^{\circ}\right)$ prior to rivalry. It is unlikely that the plaid stimuli yielded monocular rivalry. The initiation of monocular rivalry usually takes several seconds longer than the $300 \mathrm{~ms}$ duration our stimuli were presented (Breese, 1909). The gratings were also achromatic and presented at a low contrast, which further minimizes the possibility of monocular rivalry (O'Shea, Parker, La Rooy, \& Alais, 2009).

All conditions ended with a pair of static rivalrous gratings for 10 seconds. Rivalrous gratings were always oriented orthogonally ( $-45^{\circ}$ to one eye, $+45^{\circ}$ to the other eye). Given the starting position of gratings in each entrained sequence, one of the rivalrous gratings matched the preceding sequence (i.e., it was the next item in the motion sequence), while the other grating did not match the preceding sequence (i.e., it was an orientation that would be a step in the opposite motion direction). Both gratings in the rivalrous display were an equal distance away from the last non-rivalrously presented grating and only differed with respect to whether they continued the direction defined by the predictive sequence or not. Trials advanced automatically after an inter-trial interval (ITI) of $1,500 \mathrm{~ms}$.

Design The full factorial design consisted of the following conditions: Entrainment type (entrain $-45^{\circ}$, entrain $+45^{\circ}$, blank, plaid), motion direction (clockwise, counterclockwise)

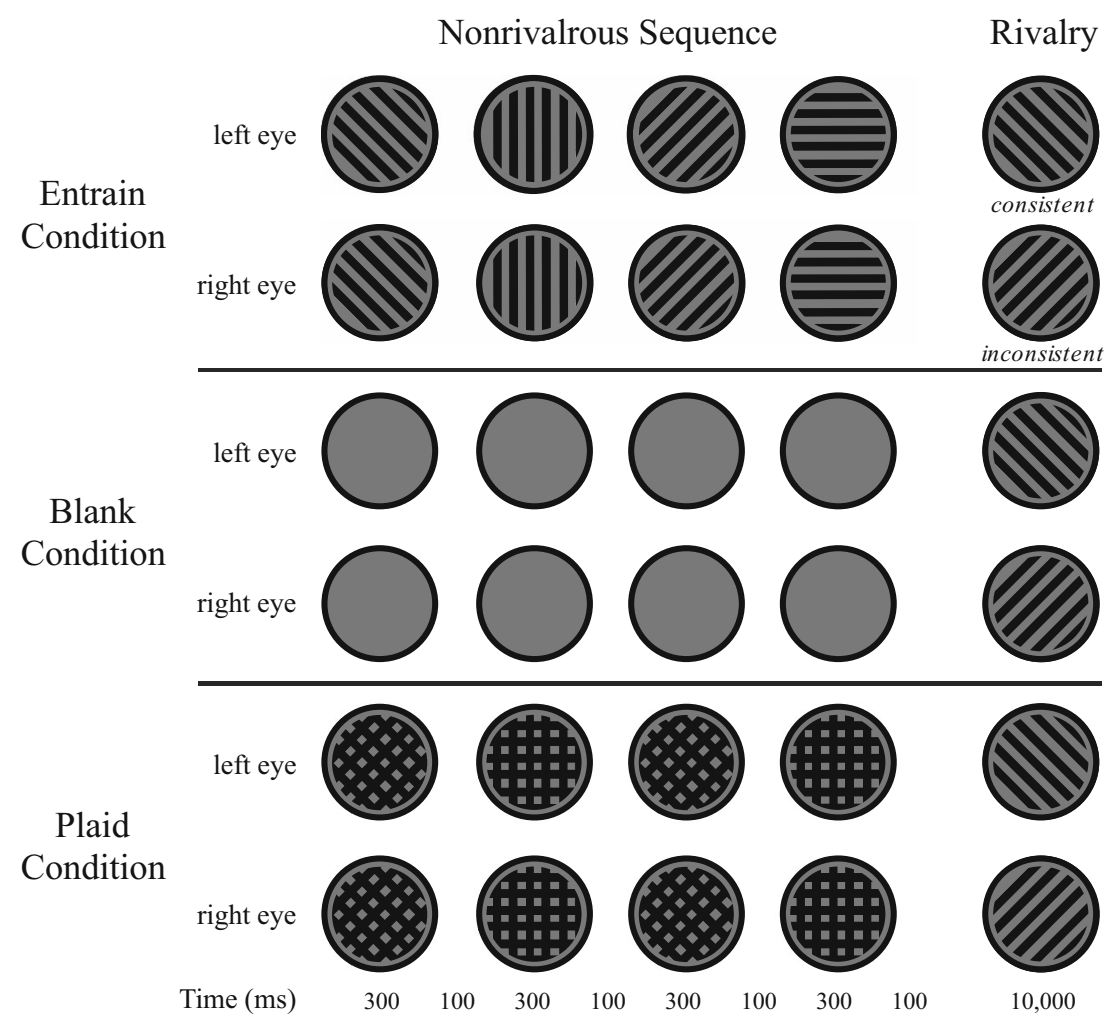

Fig. 1 Trial events for Experiments 1 and 2. Sequences of non-rivalrous stimuli were shown to the left and right eyes prior to a rivalrous display of orthogonal gratings. The stimuli were viewed through a mirror stereoscope and the frames of all sequences were presented in the center of each half of the monitor. The annulus remained on the screen for $100 \mathrm{~ms}$ between frames (omitted from the figure below for brevity). Observers reported the orientation of their dominant percept during rivalry in Experiment 1. In Experiment 2, the gratings in the rivalrous display were colored red or green and observers reported the color of their dominant percept. This change disguised the purpose of the experiment since orientation remained the factor of interest. All stimuli were presented at a contrast lower than that depicted below 
and orientation placement in the rivalrous display (left-eye -45 and right-eye +45 , left-eye +45 and right-eye -45 ). The order of these conditions was randomly mixed anew for each observer. Conditions appeared equally often. There were a total of 192 experimental observations per subject (12 in each of the 16 unique trial types). The plan was to collapse the data across the motion direction and orientation placement variables, yielding a total of 48 observations per subject in each of the 4 entrainment conditions (i.e., entrain $-45^{\circ}$, entrain $+45^{\circ}$, blank, plaid).

Task Observers continuously reported the orientation of their dominant percept for the whole duration of the rivalrous display by pressing the appropriate keys on the computer keyboard (press " $\mathrm{F}$ " for $-45^{\circ}$ with the left index finger, press " $\mathrm{J}$ " for $+45^{\circ}$ with the right index finger). Specifically, each key was pressed for as long as the corresponding percept persisted. When a perceptual transition occurred, the currently pressed key was released and the key associated with the other perceptual response was pressed. Responses were recorded in this fashion until the offset of the rivalrous display. The percept indicated by the first key press was coded as the initial dominant percept. No response was designated for mixed percepts. No emphasis was placed on the predictability of the sequence preceding the rivalry display.

Dependent measure The dependent measure was proportionconsistent responses (i.e., on entrain conditions, the consistent percept was coded as the orientation that continues the motion direction of the non-rivalrous sequence). On each of the two control conditions, responses were randomly coded as "consistent" or "inconsistent" on a trial-by-trial basis for each subject.

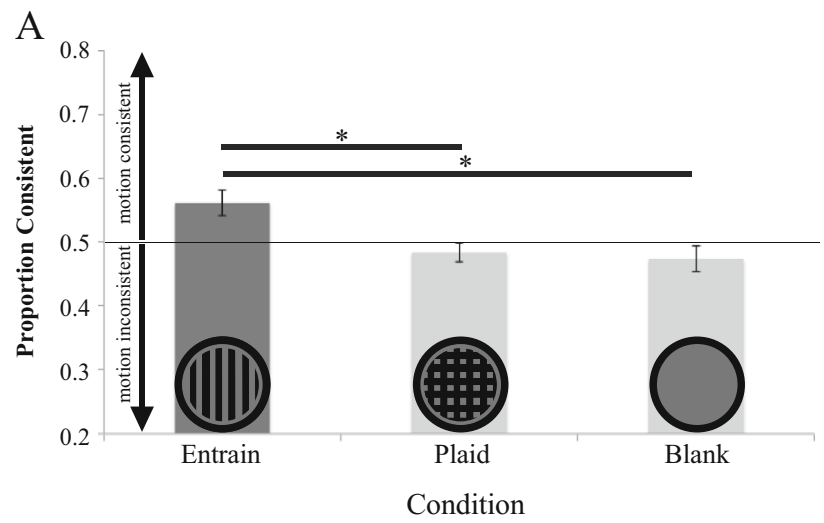

Fig. 2 Proportion consistent responses as a function of condition for Experiment 1 (left panel) and 2 (right panel). The higher proportion of motion-consistent responses in the entrain condition relative to the control
Data analysis In the experiments that follow, the underlying assumptions of statistical tests were confirmed and corrections were made if needed. Assumptions of normality and sphericity were confirmed using a one-sample Kolmogorov-Smirnov test and Mauchly's test, respectively. Assumptions of equal variances were confirmed using Levene's test. Dunn-Šidák planned comparisons, which control the family wise error rate for multiple comparisons among means, were used after significance of the final model was verified (Dunn, 1961; Šidák, 1967). These comparisons were used to test for differences in performance across the entrainment and control conditions.

Results and discussion

The resolution of onset rivalry was biased by motion direction. The results from this experiment, and all subsequent experiments, are limited to the initial dominant percept because no effects of predominance for the consistent percept were found in the sustained rivalry data beyond the initial percept (see also Denison et al., 2011).

Figure $2 \mathrm{~A}$ shows the mean proportion of reporting a motion consistent percept in the rivalrous display as a function of condition. The data were submitted to univariate repeated-measures ANOVA with condition as the factor. There was a main effect of condition, $F(2,20)=7.27$, $p=0.004, \mathrm{p}^{2}=0.421, \mathrm{MSe}=0.003$ (all KolmogorovSmirnov $p \mathrm{~s}>0.814$; Mauchly's $p=0.682$ ). Dunn-Šidák planned comparisons revealed that the entrain condition $(56 \%)$ differed from the blank $(47 \%)(p=0.008)$ and plaid $(48 \%)(p=0.029)$ conditions. The control conditions were statistically equal $(p=0.980)$.

In summary, we find that selection in onset rivalry can be entrained by temporally predictive contexts and thus provide a replication of Denison et al. (2011).

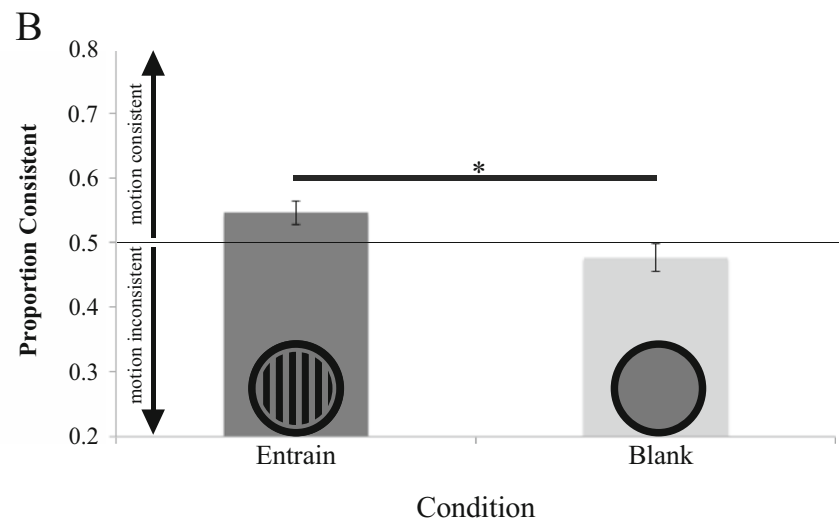

condition suggests that the resolution of onset rivalry is biased by motion direction. Error bars are standard error of the mean (SEM) 


\section{Experiment 2}

Many reported top-down effects on binocular rivalry found in the past have been criticized because phenomenological reports of the dominant percept are subjective and may be susceptible to extraneous variables (e.g., Losciuto \& Hartley, 1963; Walker, 1978; Yu \& Blake, 1992). Examples include response bias (individual differences in response threshold) and demand characteristics (observers base their answers on the perceived expectations of the experimenter). In Experiment 2, we minimized the influence of factors other than visual history by requiring that observers report the dominance of a feature (color) that was orthogonal to the one of interest (orientation). The same experimental design was used but the gratings in the rivalrous display were colored green and red. Predictive motion direction continued to bias binocular rivalry even though the purpose of the experiment was disguised.

Method

All aspects of the method were identical to Experiment 1, with the exceptions noted below.

Observers Eleven undergraduate volunteers from the University of Iowa participated in exchange for course credit (6 males, 5 females, age range: 18-23 years, 0 left-handed).

Stimuli The non-rivalrous gratings presented were the same as those described in Experiment 1. The gratings in the rivalrous display were colored red (CIE color coordinate system values: $x=0.33, y=0.31$, luminance $=26 \mathrm{~cd} / \mathrm{m}^{2}$; Tektronix model $\mathrm{J} 17$ colorimeter) and green $\left(x=0.32, y=0.38,26 \mathrm{~cd} / \mathrm{m}^{2}\right)$.

Procedure The procedure was the same as reported in Experiment 1 with two key differences. First, each rivalrous grating was colored either red or green. Second, we tested effects of entrainment only against the blank control condition because no difference was found between either of the baseline conditions tested in Experiment 1.

Design The full factorial combination of Entrainment type (entrain $-45^{\circ}$, entrain $+45^{\circ}$, blank $-45^{\circ}$, blank $+45^{\circ}$ ), motion direction (clockwise, counterclockwise), orientation placement in the rivalrous display (left-eye -45 and right-eye + 45 , left-eye +45 and right-eye -45 ), and color placement in the rivalrous display (left-eye red and right-eye green, left-eye green and right-eye red) was mixed and randomized for each observer. All conditions appeared equally often. Notice that from the point of view of the subject, the blank $-45^{\circ}$ and blank $+45^{\circ}$ conditions were identical. The designation of orientation to these baseline conditions only affected the coding of consistent percepts in the analysis (see dependent measure).
There were a total of 192 experimental observations per subject ( 6 in each of the 32 unique trial types). We collapsed the data across all counterbalancing variables to yield a total of 96 observations per subject in each of the 2 entrainment conditions of primary interest (i.e., entrain and blank).

Task Observers continuously reported the color of their dominant percept for the whole duration of the rivalrous display by pressing the appropriate keys on the computer keyboard (press "F" for red, press "J" for green). The first key press was coded as the initial dominant percept. Color was assigned independently of orientation.

Dependent measure The dependent variable again was the proportion of consistent responses. On entrain conditions, the consistent percept was coded as the orientation that continued the motion direction of the non-rivalrous sequence. For the blank $-45^{\circ}$ control condition, all reports of the $-45^{\circ}$ percept were coded as "consistent". Similarly, for the blank $+45^{\circ}$ control condition, all reports of the $+45^{\circ}$ percept were coded as "consistent." The addition of these two controls allowed us to match the number of observations to the two entrain conditions, unlike in Experiment 1.

\section{Results and discussion}

Motion direction again biased the resolution of onset rivalry. Figure $2 \mathrm{~B}$ shows the mean proportion of reporting a motion consistent percept in the rivalrous display as a function of condition. The data were submitted to univariate repeatedmeasures ANOVA with condition as the factor. There was a reliable difference between the entrain (55\%) and blank (48\%) conditions, $F(1,10)=7.42, p=0.021, \mathrm{p}^{2}=0.426$, MSe $=0.004$ (all Kolmogorov-Smirnov $p$ s $>0.853$ ). Experiment 2 shows that the results obtained in Experiment 1 were not driven by response bias or demand characteristics since reporting a feature incidental to orientation reproduced the effect.

\section{Experiment 3}

There are at least two possible explanations for the observed effects of preceding motion information on onset rivalry. Topdown factors, such as expectation, may help generate predictions of forthcoming stimuli based on the previous motion trajectory (see Denison et al., 2011 for a discussion of this topic). In contrast, low-level neural circuits between subcortical structures and early visual cortical areas may prime pattern-consistent percepts through synchronized, featurallylinked neuronal activity (e.g., Sillito, Jones, Gerstein, \& West, 1994). We propose that the involvement of top-down factors 
in onset rivalry is made more plausible to the extent that rivalry can be entrained by information that is represented at higher cortical areas not accounted for by simple early-stage circuits. Experiment 3 tested whether verbal semantic information, for which processing occurs well beyond anatomically early areas (see Vigneau et al., 2006 for a review), biases the resolution of rivalry at onset. An effect of semantic entrainment would suggest that predictive signals exist at cortical stages at least up to semantic processing.

Observers saw one of two possible verbal entrainment sequences ("they ate the" or "they pull the") immediately preceding a rivalrous display. The rivalrous display contained one word that was semantically consistent with the "ate" sentence to one eye and another word that was semantically consistent with the "pull" sentence to the other eye (Appendix). Performance was compared to a blank control condition that presented only a black frame with no semantic information. No differences in the consistency of the initial percept were observed between entrain and blank conditions, which suggests that semantic information did not influence dominance in onset rivalry.

\section{Method}

All aspects of the method were identical to Experiment 1, with the exceptions noted below.

Observers Eleven undergraduate volunteers from the University of Iowa participated in exchange for course credit (6 males, 5 females, age range: $18-21$ years, 2 left-handed). One observer was omitted for a $100 \%$ color bias to green. All were native English speakers.

Stimuli Visual stimuli were words framed by a black box to aid stable vergence $\left(2^{\circ}\right.$ height, $6.61^{\circ}$ width, $0.27^{\circ}$ frame thickness). Words presented during the nonrivalrous sequence were presented in black $\left(3 \mathrm{~cd} / \mathrm{m}^{2}\right)$ while words in the rivalrous display were presented at $30 \%$ contrast in red $(x=0.48, y=$ $\left.0.30,53 \mathrm{~cd} / \mathrm{m}^{2}\right)$ and green $\left(x=0.33, y=0.40,69 \mathrm{~cd} / \mathrm{m}^{2}\right)$. These complementary colors should facilitate grouping of the same-colored letters during the rivalry period (e.g., Kovács, Papathomas, Yang, \& Fehér, 1996). All letters were capitalized in Menlo font. The font had a fixed-width to ensure that the letters overlapped the same degree of space on corresponding retinal locations. All words in the rivalrous display were 5 letters long and measured $0.64^{\circ}$ in height and $3.64^{\circ}$ in width. Words were placed on a neutral gray background $\left(53 \mathrm{~cd} / \mathrm{m}^{2}\right)$.

Procedure Observers completed one $\sim 45$-minute session that consisted of a practice block of 7 trials, followed by 5 experimental blocks of 32 trials each. Practice trials were excluded from all analyses.
Figure $3 \mathrm{~A}$ illustrates the trials events for each condition. On entrain conditions, trials began with a predictive sequence where identical words were presented simultaneously to each eye on separate halves of the computer monitor. The predictive sequence always consisted of three sequentially presented words that either formed an ate-consistent context (THEY ATE THE) or a pull-consistent context (THEY PULL THE). Each word in the predictive sequence was presented for $400 \mathrm{~ms}$, followed by a $200 \mathrm{~ms}$ blank period where only the black frame persisted. Performance was compared to a blank condition where only the black frame preceded the rivalrous display.

A pair of static rivalrous words followed all conditions for 10 seconds. One of the words was randomly sampled, with replacement, from the ate-word list while the other word was randomly sampled from the pull-word list (Appendix). As a result, one of the words was semantically consistent with the previous sequence on entrained conditions while the other was semantically inconsistent. Trials advanced automatically after an ITI of $200 \mathrm{~ms}$.

Design The full factorial combination of consistency (ate sequence, pull sequence, blank comparison for ate, blank comparison for pull), word placement in the rivalrous display (left-eye ate and right-eye pull, left-eye pull and right-eye ate), and color in the rivalrous display (left-eye red and right-eye green, left-eye green and right-eye red) was mixed and randomized for each observer. All conditions appeared equally often. As before, the blank-ate and blank-pull baseline conditions appeared identical from the point of view of the subject. The designation of a word list to these baseline conditions only affected the coding of consistent percepts in the analysis (see dependent measure).

There were a total of 160 observations per subject (10 in each of the 16 unique trial types). We collapsed the data across all counterbalancing variables to yield a total of 80 observations per subject in each of the 2 conditions of interest (entrain and blank).

Task Observers continuously reported the color of their dominant percept for the whole duration of the rivalrous display by pressing the appropriate keys on the computer keyboard ("F" for red, "J" for green). The first key press was coded as the initial dominant percept. The variable of interest was not color but rather semantic meaning.

Dependent measure The dependent variable was the proportion of consistent responses. On entrain conditions, the consistent percept was coded as the word that was semantically congruent with the preceding non-rivalrous sequence. For the blank-ate control condition, reports of the word from the "ate list" were coded as "consistent". 
A

Ate

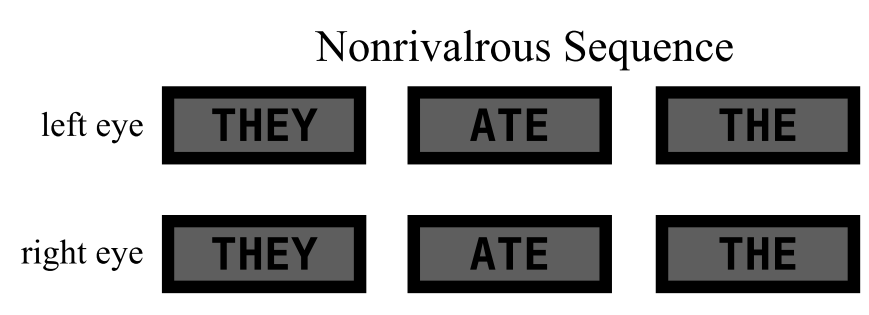

Rivalry

Condition

dition

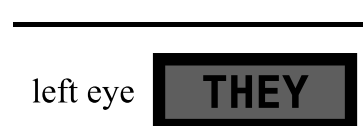

Pull

Condition
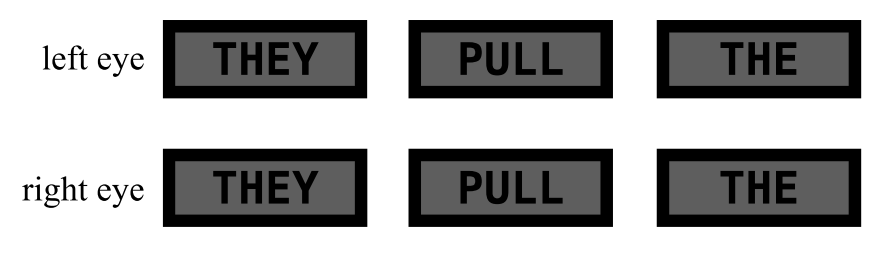

inconsistent

Condition

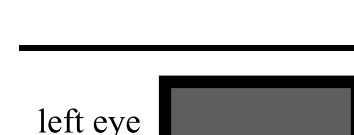

Blank

left eye
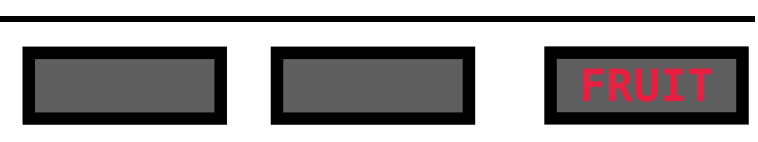

Condition

right eye

Time (ms)
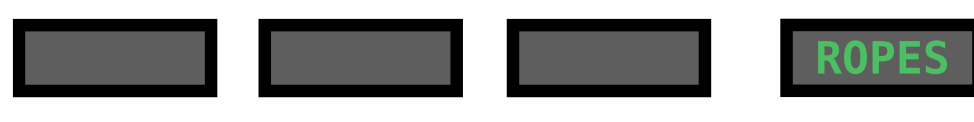

consistent

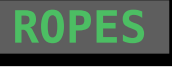

inconsistent
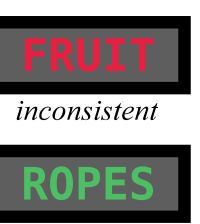

consistent

B

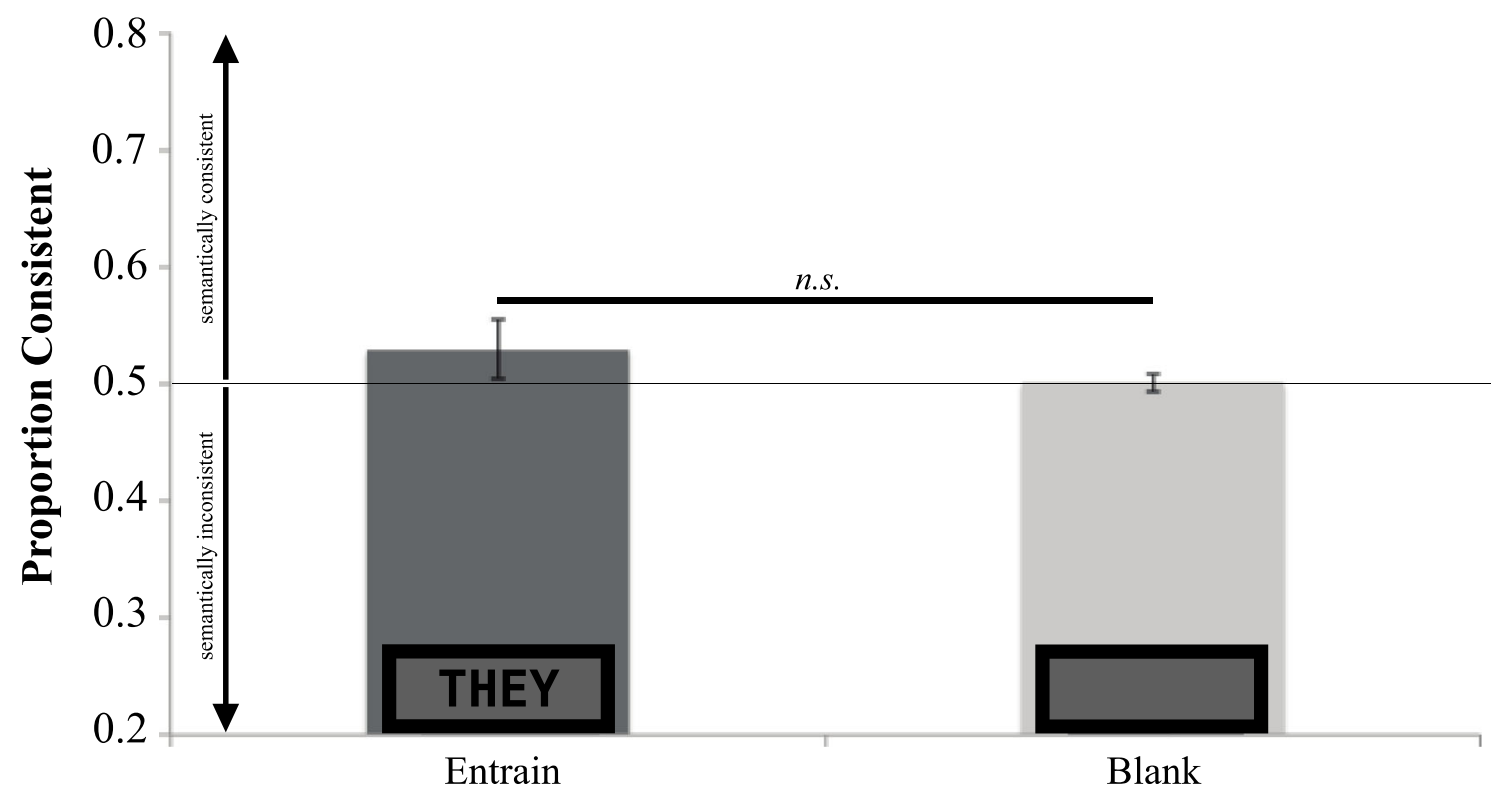

\section{Condition}

Fig. 3 A Sequences of nonrivalrous word stimuli were shown to the left and right eyes prior to a rivalrous display of colored words. One of the rivalrous words was semantically consistent with the "ate" sequence while the other was consistent with the "pull" sequence (see Appendix). Observers reported the color of their dominant percept, but semantic consistency was the factor of interest. B Proportion consistent responses as a function of condition. The equal proportion of semantically consistent and inconsistent responses between the entrain and control conditions suggests that selection in onset rivalry is not modulated by semantic congruency. Error bars are SEM
Similarly, for the blank-pull control condition, reports of the word from the "pull list" were coded as "consistent." There were therefore an equal number of observations between the entrain and blank conditions. 
Results and discussion

Onset rivalry was not entrained by semantic context. Figure 3B shows the mean proportion of reporting a semantically consistent percept in the rivalrous display as a function of condition. A univariate repeated-measures ANOVA revealed no difference between the entrain (53\%) and blank $(50 \%)$ conditions, $F(1,9)=1.03, p=0.336, \mathrm{p \eta}^{2}=0.103$, $\mathrm{MSe}=0.004$ (all Kolmogorov-Smirnov $p \mathrm{~s}>0.887$ ).

It is unlikely that the negative result between the entrain and blank conditions was due to the inability of the word stimuli to engage in rivalry. One of the initial discoveries of rivalry was observed between letter stimuli ( $\mathrm{S}$ and $\mathrm{A}$; Wheatstone, 1838) and previous work has shown rivalry to occur among words (e.g., Wolf \& Hochstein, 2011). To increase confidence that our specific word stimuli rivaled, we took several basic quantitative measurements of the rivalry period and compared these values to the data obtained in Experiment 2. Specifically, the average number of perceptual alternations during the 10 -second rivalry period was 1.4 for words (and 1.7 for gratings), the mean latency to the initial response was $1357 \mathrm{~ms}$ for words (and $1014 \mathrm{~ms}$ for gratings), and the duration of the initial response was $3023 \mathrm{~ms}$ for words (and $2827 \mathrm{~ms}$ for gratings). The data from these two experiments are comparable to the values reported in previous work (e.g., Denison et al., 2011; Wolf \& Hochstein, 2011).

In summary, we found no influence of semantic context on the perceptual resolution of rivalry when the context was defined by semantically meaningful text. In contrast to the current results, effects of semantic linguistic context on predominance during the sustained viewing of rivalrous images have been found (e.g., Wolf \& Hochstein, 2011). This suggests that the effects of semantic context, like other factors (see Stanley et al., 2011 for a review) differ between onset rivalry and sustained rivalry (Carter \& Cavanagh, 2007).

\section{Experiment 4}

The results of Experiment 3 fail to support the view that onset rivalry can be modulated by top-down factors like consistency of semantic information. The absence of semantic entrainment instead suggests that predictive signals break down prior to reaching stages of processing where semantic information is represented. On the other hand, the significant influence of motion entrainment on onset rivalry reveals that at least some predictive signals are efficacious up until at least those processing stages that are involved in perceiving motion. It follows, then, that entrainment of onset rivalry must break down at some intermediate point within the processing stream between motion and semantic processing. According to Carter and Cavanagh (2007), this point is likely to be in relatively low-level processing.

In Experiment 4, we sought to test further the power of motion entrainment on onset rivalry, by making the predictive pattern of motion more complex than the simple continuation of motion in the current direction. Specifically, rivalrous gratings were preceded by unambiguous sequences of gratings that either rotated back and forth between two oblique orientations (smooth motion) or rotated from one oblique orientation to another before abruptly returning to the original orientation and continuing in the original direction (pattern motion) (Fig. 4). Notice that for the pattern motion condition, therefore, the orientation of the next step in the patterned motion sequence was orthogonal to the orientation the grating would be if it continued in the locally defined direction of motion. Thus, if onset rivalry is biased in a manner consistent with the patterned motion, it would represent a significantly more complex entrainment process than that demonstrated by the biases observed in Experiments 1 and 2.

\section{Method}

All aspects of the stimuli and procedure were identical to Experiment 1, with the exceptions noted below.

Observers Twenty-two undergraduate volunteers from the University of Iowa participated in exchange for course credit (11 males, 11 females, age range: 18-21 years, 1 left-handed). Separate groups of 11 subjects each were assigned to one of the two entrainment conditions (smooth or pattern) so that individual subjects would be entrained in the same way throughout the experiment. We opted for this design in favor of a within-subjects approach in order to maximize the possibility of entrainment and minimize the possibility of confusion or uncertainty that might have resulted from changing the entrainment condition. Even-numbered observers saw intermixed conditions of the smooth-motion condition and the blank control, while odd-numbered observers saw intermixed conditions of the pattern-motion condition and the blank control.

Procedure Observers completed one $\sim 60$-minute session that consisted of a practice block of 7 trials, followed by 5 experimental blocks of 32 trials each. Practice trials were excluded from all analyses.

The trial events are illustrated in Fig. 4. During the nonrivalrous portion of each trial, observers saw sequences of either smooth motion or pattern motion. In the smooth motion condition, the gray gratings, unambiguously presented to both eyes, rotated smoothly back-and-forth between two oblique orientations. Three cycles were always presented. A cycle was defined as the unidirectional transition from one orientation toward its near-orthogonal orientation separated $85^{\circ}$ away 

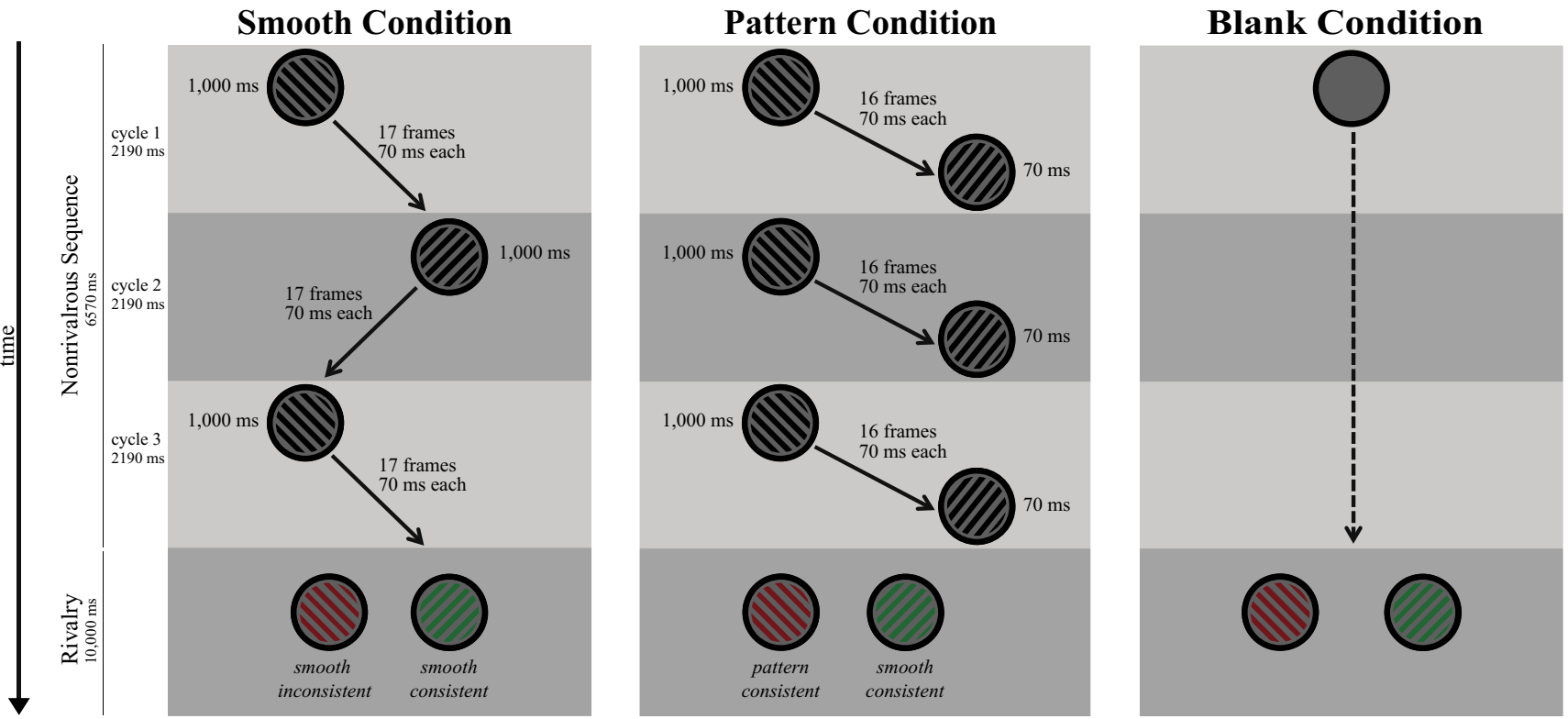

Fig. 4 Trial events for Experiments 4 and 5. In the smooth condition, the gratings rotated smoothly from one orientation to the other before returning smoothly to the original orientation and continuing in the original direction. In the pattern condition, the sequence of gratings rotated from one orientation to the other before abruptly returning to the original orientation and continuing in the original direction. The rivalrous display was presented at the point in the sequence at which the gratings either begin to reverse direction (smooth motion) or return to the original

(Fig. 4). Specifically, in cycle 1 of the smooth motion condition, the gratings rotated in increments of $5^{\circ}$ from one orientation (e.g., $\left.-45^{\circ}\right)$ to the other $\left(+40^{\circ}\right.$ in this example). In cycle 2 , the gratings started in the orthogonal direction $\left(+45^{\circ}\right)$ and returned smoothly toward the original orientation $\left(-40^{\circ}\right)$. Finally, in cycle 3 , the gratings started at the original orientation $\left(-45^{\circ}\right)$ and continued in the original direction $\left(+40^{\circ}\right)$. The gratings paused for $1,000 \mathrm{~ms}$ at each $\pm 45^{\circ}$ orientation while the duration for intervening gratings was $70 \mathrm{~ms}$ each.

In the pattern motion condition, the gray gratings rotated smoothly from one orientation to another orientation away before abruptly returning to the original orientation and continuing in the original direction. That is, in cycles 1, 2, and 3, the gratings rotated in steps of $5^{\circ}$ from one oblique orientation (e.g., $\left.-45^{\circ}\right)$ to the other $\left(+40^{\circ}\right.$ in this example). This produced the impression of an interrupted pattern sequence because the gratings instantaneously changed from the orientation seen in the last frame of the previous cycle $\left(+40^{\circ}\right)$ to the original starting orientation $\left(-45^{\circ}\right)$ at the beginning of the new cycle. The starting orientation of each cycle paused for $1,000 \mathrm{~ms}$ while all other frames were $70 \mathrm{~ms}$ each.

The rivalrous displays appeared just after the end of cycle 3 at the point where the two trajectories differed. In the pattern-motion condition, the consistent orientation was always the orientation that was presented at the start of cycle 1 orientation (pattern motion). Observers reported the color of their dominant percept, and responses were compared to a blank condition that presented only an annulus prior to rivalry. In Experiment 5, a $400 \mathrm{hz}$ tone was added to the start of each of the 3 cycles across all three conditions. The purpose of the tone was to strengthen saliency of the pattern motion information in particular. The tone was also presented simultaneously with the onset of the rivalrous display

( $-45^{\circ}$ according to the example above). In the smooth-motion condition, the consistent orientation was always the orientation that was orthogonal to the orientation presented at the start of cycle 1 (i.e., $+45^{\circ}$ ). The orthogonal gratings in the rivalry display were presented dichoptically, one in red and one in green, for 10 seconds. Trials advanced automatically after an ITI of $1,500 \mathrm{~ms}$.

Design The between-observers factor was whether the entrained sequence consisted of smooth motion or pattern motion. The full factorial combination of the following within-subjects factors were entrainment type (entrain, blank), motion direction (clockwise, counterclockwise), orientation placement in the rivalrous display (left-eye -45 and right-eye +45 , left-eye +45 and right-eye -45 ), and color placement in the rivalrous display (left-eye red and right-eye green, left-eye green and right-eye red). These factors were mixed and randomized for each observer and they appeared equally often throughout the course of the experiment. There was a total of 160 experimental observations per subject ( 5 in each of the 32 unique trial types). We collapsed the data across all counterbalancing variables to yield a total of 80 observations per subject in each of the 2 entrainment conditions of interest (i.e., entrain type [either smooth or pattern] and blank). 
Task As before, observers continuously reported the color of their dominant percept for the whole duration of the rivalrous display by pressing the " $\mathrm{F}$ " key for red and the " $\mathrm{J}$ " key for green. The manipulation of interest, however, was orientation.

Dependent measure The proportion of consistent responses was the dependent measure. "Consistent" responses were those indicating the orientation that would have continued the preceding motion sequence. Notice that the coding of consistent and inconsistent percepts differs between the smooth and pattern conditions in Fig. 4. In the smooth condition, one of the rivalrous gratings was the expected next step in the motion sequence (smooth consistent) while the other grating was inconsistent with the implied direction of the preceding motion sequence (smooth inconsistent). In contrast, notice that in the pattern condition, one of the gratings was the next step of the pattern-motion sequence as defined by the orientation after the instantaneous orientation switch (pattern consistent) while the other grating could be perceived as continuing the direction of rotation from the preceding cycle. For this reason, rivalrous displays on pattern condition trials had a pattern consistent percept and a smooth consistent percept (Fig. 4). Responses in the control condition were randomly coded as "consistent" or "inconsistent" on a trialby-trial basis for each subject. There were an equal number of observations between the entrain and blank conditions.

\section{Results and discussion}

Figure 5A shows the mean proportion of consistent percepts in the rivalrous display as a function of condition. In the smooth condition, proportions above chance $(50 \%)$ indicate reports of smooth consistent percepts while proportions below chance indicate reports of smooth inconsistent percepts. In the pattern condition, proportions above chance indicate reports of smooth consistent percepts while proportions below chance indicate reports of pattern consistent percepts. We find that rivalrous items dominated equally often during the control condition but were entrained by the next step predicted by smooth rotation, even when observers were entrained with pattern sequences.

Onset rivalry was biased by motion direction regardless of whether observers saw smooth sequences or pattern sequences. The data were submitted to a mixed ANOVA with one between-subjects factor (smooth motion vs. pattern motion) and one within-subjects factor (entrain, blank). There was a reliable difference between the entrain (59\%) and blank $(50 \%)$ conditions, $F(1,20)=17.41, p<0.001, \mathrm{p \eta}^{2}=0.465$, $\mathrm{MSe}=0.005$ (all Kolmogorov-Smirnov $p \mathrm{~s}>0.827$; Levene's test of equality of error variances $p \mathrm{~s}>0.163$ ). Critically, there was no interaction for the between- and within-subjects factors, indicating that observers reported the item consistent with smooth motion regardless of whether they saw smoothmotion sequences or pattern-motion sequences, $F(1,20)=$ $0.920, p=0.349, \mathrm{p \eta}^{2}=0.044, \mathrm{MSe}=0.005$.

In summary, the results indicate that onset rivalry can be entrained by lower-order smooth motion (i.e., next step of motion) but at least for these displays, could not be entrained by higher-order pattern motion. Even complete certainty of the pattern information that was provided by the betweensubjects design was not sufficient to override the effect of the lower-order motion information.

\section{Experiment 5}

The previous experiment showed that pattern motion failed to bias selection. This may be because pattern information does not influence onset rivalry. Alternatively, it may be because the strength of the pattern information that was provided in

A

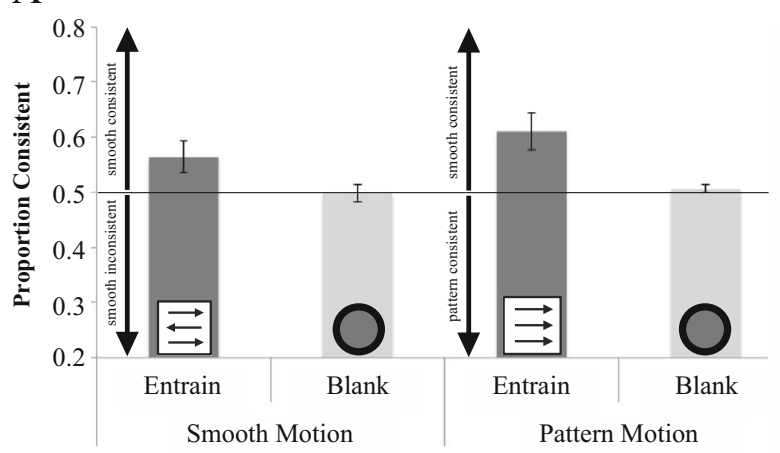

Fig. 5 Proportion consistent responses as a function of condition for Experiment 4 (left panel) and 5 (right panel). The higher proportion of smooth-motion-consistent responses in the entrain condition relative to

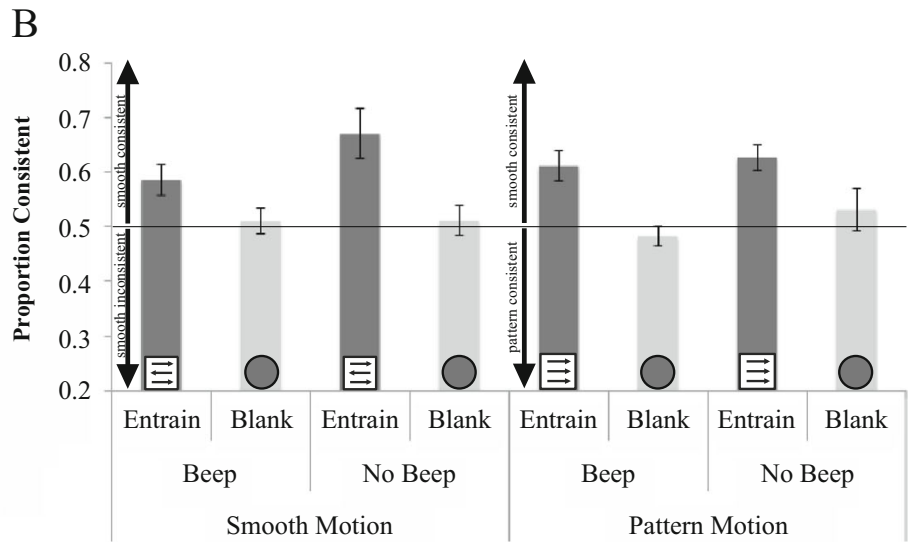

the blank condition - for both smooth and patterned sequences - suggests that the resolution of onset rivalry is not biased by pattern information. Error bars are SEM 
Experiment 4 was insufficient. Bimodal sensory integration studies (Ernst \& Bulthoff, 2004; Joassin, Maurage, Bruyer, Crommelinck, \& Campanella, 2004; see Thesen, Vibell, Calvert, \& Sterbauer, 2004 for a review) show that a visual signal is enhanced by the addition of a concurrent auditory cue. In Experiment 5, we added an auditory tone to highlight the instantaneous orientation switch that defined the pattern. Smooth motion still drove selection.

\section{Method}

All aspects of the stimuli and procedure were identical to Experiment 4, with the exceptions noted below.

Observers Twenty-two undergraduate volunteers from the University of Iowa participated in exchange for course credit ( 8 males, 14 females, age range: 18-21 years, 2 left-handed). As before, even-numbered observers saw intermixed conditions of the smooth motion condition and the blank control, while odd-numbered observers saw intermixed conditions of the pattern motion condition and the blank control.

Procedure The procedure was the same as Experiment 4 with two key differences. First, an auditory tone was presented for $150 \mathrm{~ms}$ ( $400 \mathrm{hz}, 65 \mathrm{db}, 5 \mathrm{~ms}$ ramp time to avoid clicks) at the start of each of the three cycles (Fig. 4). In the smooth-motion condition, a tone was added each time the motion direction reversed. In the pattern-motion condition, the tone was added each time the grating abruptly returned to its original starting orientation. The tone was used as a cue to strengthen perception of the pattern information. The timing of these tones was repeated in the blank condition as well. The tone was also presented simultaneously with the onset of the rivalrous display. Second, $25 \%$ of trials were replaced with catch trials in which no tone was presented. This allowed us to compare performance with and without the tone using a within-subjects error term.

There were a total of 160 observations per subject ( 5 in each of the 32 unique trial types). The data were collapsed across all counterbalancing variables for a total of 80 observations per subject in each of the 2 entrainment conditions of interest (i.e., entrain type [either smooth or pattern] and blank). For each subject, approximately 20 of the 80 observations from both of the entrain and blank trials were coded as a catch ("no beep") trials.

Task Observers continuously reported the color of their dominant percept for the whole duration of the rivalrous display by pressing the " $F$ " key for red and the "J" key for green. The factor of interest was orientation.

\section{Results and discussion}

Figure 5B shows the mean proportion of consistent percepts in the rivalrous display as a function of condition. Rivalrous items dominated equally often during the baseline conditions but were entrained by the next step predicted by the smoothmotion sequence.

Reports continued to be biased by motion direction despite the addition of the tone. The data were submitted to a mixed ANOVA with one between-subjects factor (smooth motion vs pattern motion) and two withinsubjects factors (entrain, blank; tone, no tone). The assumptions of normality $(p>0.792)$ and equality of variances were assumed for these data $(p>0.163)$. We found a reliable difference between the entrain (62\%) and blank $(51 \%)$ conditions, $F(1,20)=26.01, p<$ $0.001, \mathrm{p \eta}^{2}=0.565, \mathrm{MSe}=0.011$. There was no interaction between the entrain and blank conditions and the between-observers factor which demonstrates again that the motion consistent percept was chosen regardless of whether observers saw smooth motion or pattern motion, $F(1,20)=0.01, p=0.912, \mathrm{p \eta}^{2}=0.001$, MSe $=$ 0.011 . The presence of an auditory tone influenced the results, $F(1,20)=5.16, p=0.034, \mathrm{p \eta}^{2}=0.205$, MSe $=$ 0.006 . Specifically, smooth-consistent percepts were reported less often when there was a tone $(60 \%)$ versus when there was no tone $(65 \%)$. None of the interactions were significant.

In Experiments 4 and 5, we found no effect of pattern entrainment on onset rivalry. This may be because the selection processes that determine onset rivalry is indeed insensitive to high-level pattern information. Alternatively, those selection processes may be susceptible to influence by pattern information, but they may be more susceptible to local motion information. Our tests always pitted the two against each other. It is possible that a strong, smooth (local) motion effect might therefore have overridden a weaker pattern motion effect. Recall, however, that pattern versus smooth motion was manipulated between subjects. Therefore, observers in the pattern-motion condition never saw the sequence of motion that was consistent with the smooth motion continuation grating. Moreover, we offer the observation that in a preliminary experiment (see supplemental materials) we continued to find no effect of pattern information on rivalry when we obtained a separate measure of pattern entrainment.

In any case, these results indicate that at very least pattern-motion information was insufficiently strong to override any local direction-of-motion information these displays contained to bias selection for dominance in onset rivalry. 


\section{General discussion}

In this study, we examined how past stimulus history interacts with the selection of the initial dominant percept during onset rivalry. Across five experiments, we demonstrate that predictive signals break down early in the stream of visual processing; although selection for which percept wins can be biased by apparent (Denison et al., 2011) and smooth motion entrainment, top-down cognitive influences, defined by pattern and semantic entrainment, did not systematically resolve perceptual competition. This pattern of results is consistent with the view that onset rivalry reflects an early stage of rivalry. This stage is likely not penetrable by high-level information that originates beyond the visual system.

Based on these studies, we would like to offer a reinterpretation of the findings reported by Denison et al. (2011). Effects of motion on onset dominance may not be caused by the influence of prior knowledge on selection. Rather, simple circuits between early cortical and subcortical areas, which are based on local motion signals, not higher-order knowledge, may underlie the selection bias on onset rivalry that is caused by direction-of-motion entrainment (e.g., Sillito et al., 1994). Consistent with this, the predictive context driving the bias in the Denison et al. study was limited to the last two nonrivalrous items that immediately preceded the rivalrous display. Longer streams of motion failed to enhance the consistency effect beyond what was achieved from the two preceding frames. This is what one would expect if the effect was caused by circuits that are dependent on local information, rather than if it was caused by higher-order processes that took into account a broad predictive context (Hohwy et al., 2008; Rao \& Ballard, 1999). Future work may help to determine whether selection in onset rivalry can be biased by motioninducing sequences other than rotating motion, such as looming discs or items that smoothly transition through color space.

A central debate in the binocular rivalry literature has concerned whether competition is resolved at low-level sites (e.g., eye-based), high-level sites (e.g., cortical areas involved in perceptual interpretation), or across multiple sites of processing (Denison \& Silver, 2012; Haynes et al., 2005; Lee \& Blake, 1999; Leopold \& Logothetis, 1996; Levelt, 1965; Paffen \& Alais, 2011; Roumani \& Moutoussis, 2012; Tong et al., 2006; Wolf \& Hochstein, 2011). There is a broad consensus at this point that there is unlikely to be any single locus at which binocular rivalry is resolved. Instead, processes that are involved in dominance, suppression, and the generation of perceptual transitions probably transpire across sites that are distributed throughout the visual and cognitive system, and are therefore susceptible to multiple bottom-up and top-down factors (Abe, Kimura, \& Goryo, 2011; Blake \& Logothetis, 2002; Lumer, Friston, \& Rees, 1998; Logothetis, 1998; Ooi and He, 1999; Pastukhov \& Braun, 2011; Polonsky, Blake, Braun, \& Heeger, 2000; Tong, Nakayama, Vaughan, \& Kanwisher, 1998; Tononi, Srinivvasan, Russell, \& Edelman, 1998). These conclusions, however, have been based mainly on evidence from measures of sustained binocular rivalry. To the extent that sustained and onset rivalry are separable at a process level, the question of locus is separable (Stanley et al., 2011). The current results raise the possibility, for example, that the locus of the resolution of onset rivalry, unlike that for sustained rivalry, is more limited to early processing stages (c.f., Abe et al., 2011). Of course, this conclusion is limited to the extent that it has so far assessed only the influence of semantic and pattern motion. Nonetheless, the data taken as such, suggest an early limited locus of resolution for onset rivalry. To the extent that this holds, it would bolster the conclusion that whereas sustained rivalry has been a useful tool for studying aspects of visual processing such as feature integration, pattern completion, and visual awareness, onset rivalry might be better suited for studying fundamental visual biases and visual ambiguities (Carter \& Cavanagh, 2007; Kalisvaart et al., 2011).

We would like to end by noting that the term onset rivalry, at present, refers collectively to the initial perceptual response of dichoptic stimuli using two different experimental paradigms: one that presents dichoptic stimuli intermittently at intervals of approximately 1 second (e.g., Carter \& Cavanagh, 2007) and another that presents dichoptic stimuli continuously for longer durations (e.g., Denison et al., 2011). Future research is needed determine whether selection measured by intermittent versus continuous viewing reflects dissociable forms of initial dominance. The role these methodological differences have on onset rivalry, if any, may elucidate why some studies find an influence of top-down factors on onset selection (e.g., perceived task utility; categorical adaptation; emotional salience; objectbased attention; Chopin \& Mamassian, 2010; Gray et al., 2009; Pelekanos et al., 2011; Mitchell et al., 2004, respectively) whereas others do not. Moreover, to further validate the role of top-down influences on onset selection, future studies should replicate these effects (e.g., Gray et al., 2009; but see Sheth \& Pham, 2008) and take measures to rule out plausible alternative explanations involving low-level mechanisms.

Acknowledgments The authors thank Bob McMurray for helpful discussions on the word stimuli used in Experiment 3. This research was supported by the National Science Foundation Graduate Research Fellowship awarded to M.A. and by NSF grant BCS-0818536 to C.M.M. 


\section{Appendix}

Table 1 Rivalry word stimuli in Experiment 3 were randomly selected with replacement on each trial from the lists below. Words were presented in uppercase Menlo, a fixed-width font, and were matched in character number

\begin{tabular}{ll}
\hline Ate Word List & Pull Word List \\
\hline SUSHI & DOORS \\
BREAD & CARTS \\
JELLY & WAGON \\
SALAD & TRUCK \\
BAGEL & CARGO \\
PASTA & CHAIR \\
WRAPS & PAPER \\
FRUIT & FERRY \\
HERBS & SLEDS \\
PIZZA & KITES \\
STEAK & CORDS \\
MELON & KNOBS \\
APPLE & LABEL \\
TOAST & COVER \\
BEANS & TABLE \\
TACOS & ROPES \\
GRAPE & TRUNK \\
GRITS & NAILS \\
JERKY & TRAIN \\
MANGO & PLATE \\
ONION & SCARF \\
OLIVE & CABLE \\
PEACH & RAFTS \\
CANDY & BENCH \\
TORTE & SHIRT \\
BACON & PEASH \\
GRAVY & LEVER \\
BERRY & \\
KIWIS & TRASH \\
CHIPS & PAINT \\
\hline
\end{tabular}

tgroup

\section{References}

Abe, S., Kimura, E., \& Goryo, K. (2011). Eye- and feature-based modulation of onset rivalry caused by the preceding stimulus. Journal of Vision, 11(13), 1-18. doi:10.1167/11.13.6

Alink, A., Schwiedrzik, C. M., Kohler, A., Singer, W., \& Muckli, L. (2010). Stimulus predictability reduces responses in primary visual cortex. Journal of Neuroscience, 30(8), 2960-2966. doi:10.1523/ JNEUROSCI. 3730-10.2010

Anderson, E., Siegel, E. H., Bliss-Moreau, E., \& Barrett, L. F. (2011). The visual impact of gossip. Science (New York, N.Y.), 332(6036), 14461448. doi:10.1126/science. 1201574
Blake, R., Brascamp, J., \& Heeger, D. J. (2014). Can binocular rivalry reveal neural correlates of consciousness? Philosophical Transactions of the Royal Society, B: Biological Sciences, 369(1641), 20130211-20130211. doi:10.1146/annurev.neuro.29. 051605.113038

Blake, R., \& Logothetis, N. K. (2002). Visual competition. Nature Reviews Neuroscience, 3(1), 13-21. doi:10.1038/nrn701

Blake, R., Yang, Y., \& Westendorf, D. (1991). Discriminating binocular fusion from false fusion. Investigative Ophthalmology \& Visual Science, 32(10), 2821-2825.

Brainard, D. H. (1997). The psychophysics toolbox. Spatial Vision, 10, 433-436.

Breese, B. B. (1909). Binocular rivalry. Psychological Review, 16(6), 410.

Carter, O., \& Cavanagh, P. (2007). Onset rivalry: Brief presentation isolates an early independent phase of perceptual competition. PLoS ONE, 2(4), e343. doi:10.1371/journal.pone.0000343

Chong, S. C., \& Blake, R. (2006). Exogenous attention and endogenous attention influence initial dominance in binocular rivalry. Vision Research, 46(11), 1794-1803. doi:10.1016/j.visres.2005.10.031

Chopin, A., \& Mamassian, P. (2010). Task usefulness affects perception of Rivalrous images. Psychological Science, 21(12), 1886-1893. doi:10.1177/0956797610389190

Crick, F., \& Koch, C. (2003). A framework for consciousness. Nature Neuroscience, 6(2), 119-126. doi:10.1038/nn0203-119

Crovitz, H. F., \& Lipscomb, D. B. (1963). Dominance of the temporal visual fields at a short duration of stimulation. American Journal of Psychology, 76, 631-637.

de Jong, M. C., Kourtzi, Z., \& van Ee, R. (2012a). Perceptual experience modulates cortical circuits involved in visual awareness. European Journal of Neuroscience, 36, 3718-3731. doi:10.1111/ejn.12005

de Jong, M. C., Knapen, T., \& van Ee, R. (2012b). Opposite influence of perceptual memory on initial and prolonged perception of sensory ambiguity. PLoS ONE, 7(1), e30595. doi:10.1371/journal.pone. 0030595.g006

Denison, R. N., Piazza, E. A., \& Silver, M. A. (2011). Predictive context influences perceptual selection during binocular rivalry. Frontiers in Human Neuroscience, 5, 166. doi:10.3389/fnhum.2011.00166

Denison, R. N., \& Silver, M. A. (2012). Distinct contributions of the magnocellular and parvocellular visual streams to perceptual selection. Journal of Cognitive Neuroscience, 24(1), 246-259. doi:10. 1162/jocn_a_00121

den Ouden, H. E. M., Kok, P., \& de Lange, F. P. (2012). How prediction errors shape perception, attention, and motivation. Frontiers in Psychology, 3, 1-12. doi:10.3389/fpsyg.2012.00548

Dolan, R. J., Fink, G. R., Rolls, E., Booth, M., Holmes, A., Frackowiak, R. S., \& Friston, K. J. (1997). How the brain learns to see objects and faces in an impoverished context. Nature, 389(6651), 596-599. doi: $10.1038 / 39309$

Dunn, O. J. (1961). Multiple comparisons among means. Journal of the American Statistical Association, 56(293), 52-64. doi:10.1080/ 01621459.1961 .10482090

Ernst, M. O., \& Bülthoff, H. H. (2004). Merging the senses into a robust percept. Trends in Cognitive Sciences, 8(4), 162-169. doi:10.1016/j. tics.2004.02.002

Esterman, M., \& Yantis, S. (2010). Perceptual expectation evokes category-selective cortical activity. Cerebral Cortex (New York, N.Y. 1991), 20(5), 1245-1253. doi:10.1093/cercor/bhp 188

Fahle, M. (1982). Cooperation between different spatial frequencies in binocular rivalry. Biological Cybernetics, 44, 27-29.

Fox, R., \& Herrmann, J. (1967). Stochastic properties of binocular rivalry alternations. Perception \& Psychophysics, 2, 432-436.

Friston, K. (2005). A theory of cortical responses. Philosophical Transactions of the Royal Society of London. Series B: Biological Sciences, 360(1456), 815-836. doi:10.1098/rstb.2005.1622

Garrido, M. I., Kilner, J. M., Stephan, K. E., \& Friston, K. J. (2009). The mismatch negativity: A review of underlying mechanisms. Clinical 
Neurophysiology, 120(3), 453-463. doi:10.1016/j.clinph.2008.11. 029

Georgeson, M. A., \& Meese, T. S. (1997). Perception of stationary plaids: The role of spatial filters in edge analysis. Vision Research, 37(23), 3255-3271.

Gray, K. L. H., Adams, W. J., \& Garner, M. (2009). The influence of anxiety on the initial selection of emotional faces presented in binocular rivalry. Cognition, 113, 105-110.

Haynes, J. D., Deichmann, R., \& Rees, G. (2005). Eye-specific effects of binocular rivalry in the human lateral geniculate nucleus. Nature, 438(7067), 496-499. doi:10.1038/nature04169

Hohwy, J., Roepstorff, A., \& Friston, K. (2008). Predictive coding explains binocular rivalry: An epistemological review. Cognition, 108(3), 687-701. doi:10.1016/j.cognition.2008.05.010

Joassin, F., Maurage, P., Bruyer, R., Crommelinck, M., \& Campanella, S. (2004). When audition alters vision: An event-related potential study of the cross-modal interactions between faces and voices. Neuroscience Letters, 369(2), 132-137. doi:10.1016/j.neulet.2004. 07.067

Kalisvaart, J. P., Rampersad, S. M., \& Goossens, J. (2011). Binocular onset rivalry at the time of saccades and stimulus jumps. PLOS ONE, 6(6), e20017. doi:10.1371/journal.pone.0020017.t002

Kaplan, I. T., \& Metlay, W. (1964). Light intensity and binocular rivalry. Journal of Experimental Psychology, 67, 22-26.

Kim, Y.-J., Grabowecky, M., \& Suzuki, S. (2006). Stochastic resonance in binocular rivalry. Vision Research, 46(3), 392-406. doi:10.1016/j. visres.2005.08.009

Kovács, I., Papathomas, T. V., Yang, M., \& Fehér, A. (1996). When the brain changes its mind: Interocular grouping during binocular rivalry. Proceedings of the National Academy of Sciences of the United States of America, 93(26), 15508-15511.

Leat, S. J., \& Woodhouse, J. M. (1984). Rivalry with continuous and flashed stimuli as a measure of ocular dominance across the visual field. Perception, 13, 351-357.

Lee, S. H., \& Blake, R. (1999). Rival ideas about binocular rivalry. Vision Research, 39(8), 1447-1454.

Lee, S. H., Blake, R., \& Heeger, D. J. (2005). Traveling waves of activity in primary visual cortex during binocular rivalry. Nature Neuroscience, 8(1), 22-23. doi:10.1038/nn1365

Leopold, D. A., \& Logothetis, N. K. (1996). Activity changes in early visual cortex reflect monkeys' percepts during binocular rivalry. Nature, 379(6565), 549-553. doi:10.1038/379549a0

Lee, T. S., \& Mumford, D. (2003). Hierarchical Bayesian inference in the visual cortex. Journal of the Optical Society of America, 20(7), $1434-1448$

Levelt, W. (1965). On binocular rivalry. Soesterberg, The Netherlands: Institute for Perception RVO-TNO.

Levelt, W. J. (1967). Note on the distribution of dominance times in binocular rivalry. British Journal of Psychology, 58, 143-145.

Lin, Z., \& He, S. (2009). Seeing the invisible: The scope and limits of unconscious processing in binocular rivalry. Progress in Neurobiology, 87(4), 195-211. doi:10.1016/j.pneurobio.2008.09.002

Logothetis, N. K. (1998). Single units and conscious vision. Philosophical Transactions of the Royal Society of London. Series B: Biological Sciences, 353(1377), 1801-1818. doi:10.1098/rstb. 1998.0333

Logothetis, N. K., \& Schall, J. D. (1989). Neuronal correlates of subjective visual perception. Science (New York, N.Y.), 245(4919), 761763.

LoSciuto, L. A., \& Hartley, E. L. (1963). Religious affiliation and openmindedness in binocular resolution. Perceptual and Motor Skills, 17, 427-430

Lumer, E. D., Friston, K., \& Rees, G. (1998). Neural correlates of perceptual rivalry in the human brain. Science, 280, 1930-1934.

Maier, A., Panagiotaropoulos, T. I., \& Tsuchiya, N. (2012). Introduction to research topic - binocular rivalry: A gateway to studying consciousness. Frontiers in Human Neuroscience, 6, 1-3. doi:10. 3389/fnhum.2012.00263/full

Melloni, L., Schwiedrzik, C. M., Müller, N., Rodriguez, E., \& Singer, W. (2011). Expectations change the signatures and timing of electrophysiological correlates of perceptual awareness. Journal of Neuroscience, 31(4), 1386-1396. doi:10.1523/JNEUROSCI. 4570-10.2011

Mitchell, J. F., Stoner, G. R., \& Reynolds, J. H. (2004). Object-based attention determines dominance in binocular rivalry. Nature, 429(6990), 410-413. doi:10.1038/nature02554

Mudrik, L., Deouell, L. Y., \& Lamy, D. (2011). Scene congruency biases Binocular Rivalry. Consciousness and Cognition, 20(3), 756-767. doi:10.1016/j.concog.2011.01.001

Mueller, T. J., \& Blake, R. (1989). A fresh look at the temporal dynamics of binocular rivalry. Biological Cybernetics, 61(3), 223-232.

Näätänen, R. (1992). Attention and brain function. Hillsdale, NJ: Lawrence Erlbaum.

Ooi, T. L., \& He, Z. J. (1999). Binocular rivalry and visual awareness: The role of attention. Perception, 28(5), 551-574. doi:10.1068/p2923

O'Shea, R. P., Kornmeier, J., \& Roeber, U. (2013). Predicting visual consciousness electrophysiologically from intermittent binocular rivalry. PLoS ONE, 8(10), e76134. doi:10.1371/journal.pone.0076134.s005

O'Shea, R. P., Parker, A., La Rooy, D., \& Alais, D. (2009). Monocular rivalry exhibits three hallmarks of binocular rivalry: Evidence for common processes. Vision Research, 49(7), 671-681. doi:10.1016/j. visres.2009.01.020

Paffen, C. L. E., \& Alais, D. (2011). Attentional modulation of binocular rivalry. Frontiers in Human Neuroscience, 5, 105. doi:10.3389/ fnhum.2011.00105

Pastukhov, A., \& Braun, J. (2011). Cumulative history quantifies the role of neural adaptation in multistable perception. Journal of Vision, 11(10), 1-10. doi:10.1167/11.10.12

Pearson, J., \& Brascamp, J. (2008). Sensory memory for ambiguous vision. Trends in Cognitive Sciences, 12(9), 334-341. doi:10.1016/ j.tics.2008.05.006

Pelekanos, V., Roumani, D., \& Moutoussis, K. (2011). The effects of categorical and linguistic adaptation on binocular rivalry initial dominance. Frontiers in Human Neuroscience, 5, 187. doi:10. 3389/fnhum.2011.00187

Pelli, D. G. (1997). The Video Toolbox software for visual psychophysics: Transforming numbers into movies. Spatial Vision, 10, 437-442.

Polonsky, A., Blake, R., Braun, J., \& Heeger, D. (2000). Neuronal activity in human primary visual cortex correlates with perception during binocular rivalry. Nature Neuroscience, 3, 1153-1159.

Rao, R. P., \& Ballard, D. H. (1999). Predictive coding in the visual cortex: A functional interpretation of some extra-classical receptive-field effects. Nature Neuroscience, 2(1), 79-87. doi:10.1038/4580

Roumani, D., \& Moutoussis, K. (2012). Binocular rivalry alternations and their relation to visual adaptation. Frontiers in Human Neuroscience, 6, 35. doi:10.3389/fnhum.2012.00035

Sheth, B. R., \& Pham, T. (2008). Vision research. Vision Research, 48(23-24), 2415-2424. doi:10.1016/j.visres.2008.07.013

Šidák, Z. K. (1967). Rectangular confidence regions for the means of multivariate normal distributions. Journal of the American Statistical Association, 62(318), 626-633. doi:10.1080/01621459.1967.10482935

Sillito, A. M., Jones, H. E., Gerstein, G. L., \& West, D. C. (1994). Feature-linked synchronization of thalamic relay cell firing induced by feedback from the visual cortex. Nature, 369(6480), 479-482. doi: $10.1038 / 369479 \mathrm{a} 0$

Song, C., \& Yao, H. (2009). Duality in binocular rivalry: Distinct sensitivity of percept sequence and percept duration to imbalance between monocular stimuli. PLOS ONE, 4(9), e6912. doi:10.1371/ journal.pone. 0006912

Stanley, J., Forte, J. D., Cavanagh, P., \& Carter, O. (2011). Onset rivalry: The initial dominance phase is independent of ongoing perceptual alternations. Frontiers in Human Neuroscience, 5, 1-9. doi:10.3389/ fnhum.2011.00140/abstract 
Stefanics, G., \& Czigler, I. (2012). Automatic prediction error responses to hands with unexpected laterality: An electrophysiological study. NeuroImage, 63(1), 253-261. doi:10. 1016/j.neuroimage.2012.06.068

Stefanics, G., Kremlacek, J., \& Czigler, I. (2014). Visual mismatch negativity: a predictive coding view. Frontiers in Human Neuroscience, B, 1-19. doi:10.3389/fnhum.2014.00666/abstract

Summerfield, C., \& Koechlin, E. (2008). A neural representation of prior information during perceptual inference. Neuron, 59(2), 336-347. doi:10.1016/j.neuron.2008.05.021

Thesen, T., Vibell, J. F., Calvert, G. A., \& Sterbauer, R. A. (2004). Neuroimaging of multisensory processing in vision, audition, touch, and olfaction. Cognitive Processing, 5(2), 84-93. doi:10.1007/ s10339-004-0012-4

Tong, F., \& Engel, S. A. (2001). Interocular rivalry revealed in the human cortical blind-spot representation. Nature, 411(6834), 195-199. doi: $10.1038 / 35075583$

Tong, F., Meng, M., \& Blake, R. (2006). Neural bases of binocular rivalry. Trends in Cognitive Sciences, 10(11), 502-511. doi:10. 1016/j.tics.2006.09.003

Tong, F., Nakayama, K., Vaughan, J. T., \& Kanwisher, N. (1998). Binocular rivalry and visual awareness in human extrastriate cortex. Neuron, 21, 753-759.

Tononi, G., Srinivvasan, R., Russell, D. P., \& Edelman, G. M. (1998). Investigating neural correlates of conscious perception by frequencytagged neuromagnetic responses. Proceedings of the National Academy of Sciences of the United States of America, 95(3198), 3203.

van Ee, R. (2009). Stochastic variations in sensory awareness are driven by noisy neuronal adaptation: Evidence from serial correlations in perceptual bistability. Journal of the Optical Society of America. A, Optics, Image Science, and Vision, 26, 2612-2622.

Vigneau, M., Beaucousin, V., Hervé, P. Y., Duffau, H., Crivello, F., Houdé, O., Mazoyer, B., \& Tzourio-Mazoyer, N. (2006). Metaanalyzing left hemisphere language areas: Phonology, semantics, and sentence processing. Neurolmage, 30(4), 1414-1432. doi:10. 1016/j.neuroimage.2005.11.002

Wacongne, C., Changeux, J.-P., \& Dehaene, S. (2012). A neuronal model of predictive coding accounting for the mismatch negativity. Journal of Neuroscience, 32(11), 3665-3678. doi:10.1523/JNEUROSCI. 5003-11.2012

Walker, P. (1978). Binocular rivalry: Central or peripheral selective processes? Psychological Bulletin, 85, 376-389.

Wheatstone, C. (1838). Contributions to the physiology of vision - part the first. On some remarkable, and hitherto unobserved, phenomena of binocular vision. Philosophical Transactions of the Royal Society of London. Series B: Biological Sciences, 128, 371-394.

Wilson, H. R., Blake, R., \& Lee, S. H. (2001). Dynamics of travelling waves in visual perception. Nature, 412(6850), 907-910. doi:10. $1038 / 35091066$

Wolf, M., \& Hochstein, S. (2011). High-level binocular rivalry effects. Frontiers in Human Neuroscience, 5, 1-9. doi:10.3389/fnhum. 2011.00129/abstract

Wolfe, J. M. (1983). Influence of spatial frequency, luminance, and duration on binocular rivalry and abnormal fusion of briefly presented dichoptic stimuli. Perception, 12(4), 447-456.

Yu, K., \& Blake, R. (1992). Do recognizable figures enjoy an advantage in binocular rivalry? Journal of Experimental Psychology: Human Perception and Performance, 18, 1158-1173. 